\title{
¿Qué diría Bomberito? Sátira política televisiva y transición democrática en México
}

\section{What would Bomberito say? Televised political satire and democratic transition in Mexico}

\author{
Dra. Frida V. Rodelo \\ Universidad de Guadalajara. México. \\ frida.rodelo@academico.udg.mx \\ https://orcid.org/0000-0002-7547-2446
}

\begin{abstract}
Resumen
Los campos de los medios de comunicación y el periodismo han sufrido grandes transformaciones a nivel mundial desde mediados del siglo XX. Diferentes tendencias mundiales han incidido en la generación, importación y reinterpretación simultánea de formatos de sátira política televisiva en distintos puntos del orbe. En México, las postrimerías de la transición política han atestiguado una presencia creciente de programas de sátira política en las parrillas de la televisión abierta y un aumento de audiencias que la consumen y que se informan a través de esta. La sátira política es un objeto de estudio interesante porque la observación de sus cualidades permite entrever las libertades y, por ende, también los constreñimientos a los que está sometida la expresión de la opinión política a través de la televisión en un periodo de apertura democrática. Partiendo del reconocimiento tanto de los mencionados cambios globales como de las condiciones internas que dieron forma al sistema de medios mexicano, así como de la construcción de una narrativa sobre el desarrollo de la sátira televisiva en el periodo de transición democrática, este estudio identifica las principales condiciones de orden institucional y organizacional que en el marco de la transición democrática dieron forma a esta modalidad de comunicación.
\end{abstract}

\begin{abstract}
The fields of media and journalism have undergone major transformations globally since the mid-20th century. Different global trends have influenced the generation, arrival and simultaneous reinterpretation of television political satire formats in different parts of the world. In Mexico, the aftermath of the political transition has witnessed a growing presence of political satire programs on broadcast television and an increase in audiences that consume and inform themselves through it. Political satire is an interesting object of study because the observation of its qualities allows us to glimpse the freedoms and, therefore, also the constraints to which the expression of political opinion through television is subjected in a period of democratic openness. Based on the recognition of both the aforementioned global changes and the internal conditions that shaped the Mexican media system, as well as the construction of a narrative on the development of television satire in the period of democratic transition, this study identifies the main institutional and organizational conditions that during the democratic transition gave shape to this mode of communication.
\end{abstract}

Palabras clave: Televisión; Sátira política; Democratización; Entretenimiento

Keywords: Television; Political satire; Democratization; Entertainment 


\section{Introducción}

El periodo posterior a la alternancia política en México ha atestiguado una presencia creciente de programas de sátira política en las parrillas televisivas; asimismo, un aumento de las audiencias que la consumen y que se informan a través de esta. Esto no es casualidad, pues los campos de los medios de comunicación y el periodismo han sufrido grandes transformaciones a nivel mundial desde mediados del siglo XX y, en específico, diferentes tendencias mundiales han incidido en la generación, importación y reinterpretación de formatos de sátira política televisiva en distintos puntos del orbe (Baym \& Jones, 2012).

El entretenimiento no es ni apolítico, ni inofensivo. Esto no implica, sin embargo, idealizar esta forma de comunicación, pues la sátira se encuentra sometida, al igual que otras formas de comunicación pública a condiciones que determinan características clave tales como los actores políticos que son objeto de la sátira, los comportamientos y cualidades causantes de la crítica y el nivel de ataque o agresividad de esta. Ridiculizar, atacar y juzgar a actores con poder a través de la comedia mediada es un acto que requiere del ejercicio de la libertad de expresión. Las cualidades de la sátira política permiten entrever las libertades y, por ende, también los constreñimientos a los que está sometida la expresión de la opinión política. Siguiendo este razonamiento, la sátira nos permite examinar de esta manera el periodo de apertura democrática en México, en donde comenzaron a atestiguarse fuertes competencias político-electorales. Además de permitir inferir los espacios de libertad que esta ocupa, examinar la sátira televisada permite inferir las maneras en que esta reproduce las condiciones de los sistemas político y de medios.

La literatura ha recuperado y reflexionado sobre cómo diferentes expresiones del humor político con rica tradición de humor transgresor, como lo son la caricatura política y la sátira política en el cine y en el teatro, han fungido como espacios para posicionar discursos de crítica que se contraponen a los discursos promovidos desde los poderes establecidos y que, por ende, tienen cierto potencial para contribuir, desde el pluralismo, al gobierno democrático (Alzate, 2010; Barajas \& Valdés, 2016). Sin embargo, escasea la reflexión centrada específicamente en la contribución a la vida pública de la sátira política televisada en el contexto mexicano (una excepción de esto es Alonso [2015]).

Este trabajo pretende llenar ese hueco, pues, a partir de la construcción de una narrativa sobre el desarrollo de la sátira política televisada en el periodo post transición democrática, ofrece indicios para concebir la limitada libertad de los programas de sátira en la televisión abierta en el periodo de transición democrática como un espacio que debe su complejidad y constante transformación a conjunciones de condiciones de orden institucional y organizacional entre las que enfatizamos cinco: las relaciones clientelares entre las televisoras y los actores políticos, la autocensura, las orientaciones políticas de los medios, las consideraciones comerciales y los rituales profesionales.

Para simplificar, he usado la palabra sátira, en singular, a lo largo de este trabajo. Esto, para referir productos manifestados primordialmente en programas televisivos de sátira política en diferentes cadenas televisivas durante un periodo de veinte años; es decir, se trata de un objeto complejo y dinámico que responde a condiciones histórico-estructurales y que se manifiesta principalmente a través de tres formatos - programas de parodia, falso noticiario y talk show-y en un abanico de tono que va de la sátira inofensiva y ligera -la más común en las pantallas mexicanas - a la sátira ácida y punzante con repercusiones políticas -ejemplificada en el estilo desarrollado por el payaso Brozo. 


\section{La sátira televisada en un contexto de cambio desde lo global y lo local}

En este apartado planteo las características elementales de la sátira, especifico los cambios globales que han dado pauta a su popularización en la televisión y señalo las condiciones económico-políticas que influencian los contenidos de los medios en el contexto post autoritario mexicano.

La sátira es una forma de comedia que suele tener como rasgos principales la risa, el juicio, el juego y el ataque (Becker, 2012). Mediante el humor se minimiza al objeto de sátira y se evoca hacia este el desdén o el ridículo (LaMarre, 2014). Pero no basta con provocar risa: la sátira suele tener como propósito final educar, entretener y persuadir (Holbert et al., 2011) y el ofrecer una perspectiva crítica sobre la realidad. Esta crítica es establecida no desde el discurso legitimado (científico o periodístico) sino desde un discurso en el que las personas comunes pueden participar (Kuhlmann, 2012; Alonso, 2015). La risa y la crítica se logran mediante el juego, que suele consistir en exagerar lo que es conocido para evidenciar sus fallas. También hay juego en el efecto de suspensión temporal del orden y de subversión del poder, que se da cuando quien detenta el poder es ridiculizado y vuelto simbólicamente vulnerable (Dinc, 2012; Ibrahim \& Eltantawy, 2017; Kuhlmann, 2012). Dado que cualquiera puede participar en el juego de la sátira, este es un espacio discursivo que permite la libertad (Dinc, 2012)

La sátira hace evidentes los límites de la tolerancia gubernamental y su respeto a la libertad de expresión (Kuhlmann, 2012), pues a través de esta pueden denunciarse los abusos de poder y señalarse la incompetencia, vicios y deficiencias de quienes detentan el poder (Alonso, 2015; Semati, 2012). Puede incluso llegar a ser una herramienta para la disidencia y la resistencia en contextos autoritarios (Kuhlman, 2012; Ibrahim \& Eltantawy, 2017). Sin embargo, la sátira también puede tener como consecuencia el reforzamiento del statu quo cuando se centra en atacar a actores políticos por rasgos personales o errores triviales en vez de usarse para fomentar el debate sobre temas sustantivos de la vida pública.

En su vertiente televisada, la sátira política se ha vuelto un género popular y con gran influencia política no solo en democracias occidentales como la estadounidense, con éxitos como The Daily Show, sino en países con regímenes autoritarios y post autoritarios en donde se presume una menor libertad para los discursos que atacan o critican a la autoridad. Ciertos cambios globales han dado pauta al surgimiento simultáneo de sátira política televisada en diferentes puntos del mundo a través de un "flujo global" de formatos reinterpretados localmente (Baym \& Jones, 2012). Cambios globales entre los que destacan ciertos avances tecnológicos y transformaciones culturales.

Los avances tecnológicos brindan el sustento material para la distribución de contenidos alternativos y la formación de públicos ante situaciones de censura estatal (Semati, 2012) y de conformismo de las televisoras abiertas y públicas (Baym \& Jones, 2012). Tecnologías como la televisión por cable y el internet han sido la base de nuevos esquemas de distribución de contenidos que son más difíciles de controlar por los poderes hegemónicos. Cuando estos esquemas son legales, las empresas que los instalan buscan competir, siguiendo una lógica de libre mercado, a través de contenidos novedosos (Martin et al., 2028). La entrada de nuevos jugadores a los mercados de medios puede fungir, en un segundo momento, como presión para que los jugadores dominantes en el sistema de medios también opten por innovar o "liberalizar" sus contenidos (Baym \& Jones, 2012; Brunn, 2012).

Ciertas transformaciones en los sistemas de medios hicieron la sátira más apetecible para las audiencias y para las organizaciones de medios. La comercialización de las organizaciones de medios (Hallin \& Mancini, 2004) es una tendencia mundial que a través de la lógica de búsqueda de ganancias tiende a ocasionar el ablandamiento e hibridación de los contenidos informativos (Otto et al., 2016). Sumándose a lo anterior, los escándalos de corrupción en los medios 
informativos y la pérdida de audiencias han dado pie a una pérdida de legitimidad del periodismo (Feldman, 2007). Esta situación ha generado un terreno propicio para el surgimiento de formas diversas de comunicación pública alternas al periodismo y que rivalizan con este, entre estas los programas televisivos de sátira política (Rodelo, 2020).

Las anteriores son algunas dimensiones de la globalización que se manifiestan en el desarrollo de los medios en la región latinoamericana y que se conjugan con condiciones internas que constriñen y dan forma a los contenidos (Waisbord, 2014). Una de las características clave de la relación entre medios y poder público en México y en América Latina es la instrumentalización de los medios, es decir, "el control de los medios por actores externos... que los usan para intervenir en el mundo de la política" (Hallin \& Mancini, 2004, p. 37). Esta puede realizarse a través de alianzas medios-gobierno, el uso político de los medios públicos, el uso discrecional de la publicidad oficial y chantajes de los medios para conseguir contratos públicos (Gómez, 2020).

Con cierta presencia incipiente en México desde su etapa autoritaria, la sátira política televisada cobró mayor visibilidad como género a partir de la década de 1990, coincidiendo con importantes transformaciones del régimen político mexicano. De ser considerado un régimen autoritario de partido único (Levitsky \& Way, 2010), el país viró hacia un sistema democrático post-autoritario "inseguro" (Hughes et al., 2017) con un sistema de medios clientelar altamente concentrado en escasos jugadores, limitado en su pluralismo y con aspiraciones liberales (Gómez, 2020); o bien, un sistema de medios "liberal capturado" (Guerrero \& Márquez, 2014).

El modelo liberal capturado puede "contarse" a través de una historia, común para los sistemas latinoamericanos, que tiene dos tiempos: en un primer acto, bajo el autoritarismo el Estado impone un "doble estándar" que impide la existencia de una prensa crítica y al mismo tiempo participa en una relación clientelar con las organizaciones de medios en la que logra controlar a estas mediante subsidios, contratos y otras formas de beneficio. En un segundo acto, nuevos actores arriban al poder político en un contexto de competitividad electoral y auge del marketing y se relacionan con jugadores mediáticos ya consolidados, de tal manera que ambos construyen arreglos renovados que responden a las necesidades de ambos: los primeros, llegar al poder y diseminar su mensaje; los segundos, conservar sus privilegios (Guerrero \& Marquez-Ramirez, 2014).

El caso de México encaja muy bien en esta historia, pues en este figura un dominio oligopólico de los medios de comunicación y una relación simbiótica o de mutuo beneficio entre las empresas de medios dominantes y los gobiernos tanto federal como estatales - dominio que continúa tras la alternancia política y tras la apertura económica y política que trajo mayor competencia en los sectores de medios. En este contexto, se ha configurado una relación medios-gobierno en la que persisten viejas prácticas asociadas con el ya mencionado clientelismo (Gómez, 2020).

En las páginas siguientes se relatará el desarrollo de la sátira en México antes y durante su transición a la democracia para de esta manera identificar indicios de la influencia de condiciones asociadas con los rasgos de los sistemas político y de medios mexicanos. Esta narrativa fue construida a partir de un proceso sistemático e iterativo de análisis de datos que incluyó la búsqueda, organización y lectura de documentos, la codificación temática para identificar las condiciones relevantes para el desarrollo de la sátira televisiva y, finalmente, la elaboración de líneas del tiempo que permitan relacionar sucesos específicos con las condiciones imperantes en el momento. Se utilizaron como fuentes de datos la hemerografía y literatura sobre la sátira en México, así como las propias grabaciones de programas de sátira disponibles en plataformas de video bajo demanda como Youtube y Blim.

\section{El desarrollo de la sátira política televisiva en México}


Los antecedentes de la sátira política televisiva en México se hayan en una rica tradición de sátira política, por un lado, en la prensa escrita (a través de la caricatura política, la columna y otros géneros periodísticos) y, por otro lado, en los espectáculos escénicos populares, como lo fueron el teatro de revista y el teatro de carpas (Barajas \& Valdés, 2016). A pesar de que el cine fue durante el siglo XX "uno de los principales escaparates de la cultura del humor en México" (Barajas \& Valdés, 2016, p. 12), la producción de películas de sátira política fue mínima. La explicación de lo anterior recae en el autoritarismo del régimen político mexicano:

El régimen posrevolucionario era reacio a la crítica y estaba muy metido en el cine, de modo que, a pesar de que el humor político tenía un público importante, se produjeron muy pocas películas de sátira política. Durante décadas, fueron pocos los realizadores que se atrevieron a tocar la figura presidencial y, cuando criticaron al régimen, lo hicieron de manera indirecta, con metáforas, circunloquios o generalizaciones; el centro de sus críticas fueron figuras menores (burócratas, presidentes municipales o agentes corruptos). Incluso los cómicos que en la carpa atacaban frontalmente a ministros y presidentes tuvieron actuaciones moderadas en la pantalla grande (Barajas \& Valdés, 2016, p. 188).

Así como en el cine mexicano la sátira política fue ínfima, el desarrollo de sátira política en la televisión fue también casi nulo debido al control que el régimen mexicano de partido único ejerció sobre este sector de medios a partir de una fuerte alianza entre el régimen y Televisa —la empresa televisiva dominante-, que funcionaba gracias a la casi total ausencia de competencia (Schmidt, 1996; Hernández \& Orozco, 2007). Los antecedentes de la sátira política televisiva se remiten al trabajo de los comediantes Héctor Lechuga y Chucho Salinas, ambos formados en los espectáculos de las carpas. Transmitido por Telesistema Mexicano -empresa precursora de Televisa- durante la década de 1960, Chucherías fue un programa en que Salinas y Lechuga se las ingeniaron para incluir rutinas de sátira política en donde se burlaban de la cultura mexicana de la corrupción. En estos, una persona común, interpretada por Lechuga, es entrevistada por Salinas sobre su vida cotidiana. El personaje de Lechuga, conforme contesta las preguntas, empieza a relatar con naturalidad sus experiencias de "mochadas" (es decir, sobornos y cuotas ilegales) y el involucramiento de jefes, mientras Salinas exclama: “¡No, no, no! ¡No me diga nombres!". Otra rutina con mensaje político fue la del personaje Juan Derecho, un súper héroe que con su látigo castigaba a corruptos, restableciendo así la justicia (Mejía, 1999).

Además de expresar la naturaleza subrepticia del fenómeno de la corrupción, los no me diga nombres y eso no me interesa hacían guiños a la censura a la que estaban sujetos los programas de televisión. Un lugar común en numerosas fuentes es la anécdota del desliz del comediante Manuel el Loco Valdés, quien en El show del Loco (1972-1974) se atreviera a bromear sobre el presidente "Bomberito Juárez" y su esposa "Manguerita". Las consecuencias de la injuria contra el héroe nacional varían según la crónica, pero no así el que la televisora tomó acciones para disciplinar a Valdés (Schmidt, 1996). Algo similar es relatado sobre el comediante Héctor Suárez, quien fuera despedido tras hacer un chiste en televisión sobre el presidente Carlos Salinas (19881994) (Schmidt, 1996). Sobre su relación con el anterior presidente —Miguel de la Madrid, 19821988-, Suárez dice: "Cuando estaba en ¿Qué nos pasa? me llamó y me dijo de una manera velada que dejara ese tipo de análisis. Que no debería ser, que nos veía el mundo entero. Que la ropa sucia se lava en casa. Obviamente no le hice caso" (Del Collado, 2013, 9 de junio).i"

Los programas de comedia ¿Qué nos pasa? (Televisa, 1985-1987) y La caravana (Imevisión, 1988-1992), con las actuaciones de Héctor Suárez, y Víctor Trujillo y Ausencio Cruz, respectivamente, incluirían rutinas cómicas con comentarios de crítica social. En varias de las rutinas de ¿Qué nos pasa?, en específico, permea la crítica hacia ciertos males sociales: la incivilidad, la ineptitud, la corrupción; en estas con frecuencia se confrontan personajes humildes con personajes de clase media. Sin embargo, como bien anota Toussaint (1986, 19 de abril), esta 
crítica hacia las fallas individuales no llegaba a tocar a las instituciones ni a las grandes estructuras sociales que permiten y fomentan tales males.

\subsection{Sátira y transición política}

Si bien se conoce el trabajo pionero de varios programas televisivos de infoentretenimiento con sátira política en países occidentales como Estados Unidos y el Reino Unido, en la televisión mexicana la sátira se manifestó a través de una cantidad significativa de programas a partir de la última década del siglo XX, lo que coincidió con una mayor claridad acerca del rumbo del proceso de transición democrática en el país. Tal tendencia se dio como parte de una mayor apertura y pluralismo informativos en los contenidos de la televisión abierta mexicana. Los mencionados cambios televisivos pueden encontrar su principal explicación en el acceso de un nuevo jugador al monopólico mercado de la televisión abierta mexicana dominado por la empresa Televisa. Como parte de la tendencia de la política neoliberal implementada por el gobierno de Carlos Salinas de Gortari (1988-1994), el gobierno federal vendió en 1993 la cadena del Instituto Mexicano de la Televisión (Imevisión), que pasó a convertirse en Televisión Azteca.

El entorno cambió en la década de 1990: por un lado, hubo una inédita competencia entre televisoras por las audiencias, y así también entre partidos por el voto de los electores, en contextos electorales por primera vez competitivos que dieron paso a que creciera el interés por la comunicación y la mercadotecnia políticas a través de la televisión (Mejía, 1999, p. 58-59). La creciente mediatización de las campañas electorales; en particular, el desarrollo de la mercadotecnia política y el gasto creciente en propaganda electoral (Mejía, 1999; Lawson, 2002; Hernández \& Orozco, 2007) fueron tendencias que asimismo dieron un desmesurado poder político a las mencionadas empresas televisoras en la siguiente década, lo que eventualmente conduciría a la manipulación del proceso electoral 2005-2006 y a una reforma electoral posterior que intentó poner freno a los abusos percibidos (Buendía \& Azpiroz, 2011).

La turbulencia política de la época también jugó su parte. 1994 fue considerado un año de ruptura debido a la conjunción de importantes eventos políticos que fueron interpretados como la pérdida del control hegemónico del PRI, entre estos los magnicidios del candidato "oficial" Luis Donaldo Colosio y del secretario general del PRI José Francisco Ruiz Massieu y el levantamiento zapatista en Chiapas. Según relata el comediante Víctor Trujillo, en una suerte de epifanía él y su productora, Carolina Padilla, decidieron el día del asesinato de Colosio que ya era "el momento" de que el personaje del payaso Brozo reemplazara la parodia ácida de cuentos infantiles que lo hiciera famoso en el programa La caravana por la sátira de las noticias de actualidad:

¿Por qué? Porque hoy se rompió el sistema. [...] Mataron al candidato del PRI. El sistema se rompió. Ve tú a saber si es una bala de afuera o es una bala de adentro. Está roto el sistema. Todo mundo va a estar distraído tratando de juntar los pedazos del sistema y no se van a dar cuenta si entramos. Cuando se den cuenta, ya estamos dentro. Y en efecto. Hablamos con... con Grupo Acir. Con los señores Ibarra. Y aceptaron (TVUDLAP, 2016).

También con este telón de fondo, en televisión, la recién llegada Azteca experimentó con nuevos formatos, estilos televisivos y temas, ejerciendo de esta manera cierta presión hacia Televisa, que además pasaba en esos momentos por dificultades financieras (Lawson, 2002; Hernández \& Orozco, 2007). Azteca incursionó, de esta manera, con un noticiario estelar amarillista, telenovelas con temas que eran considerados tabú, los infoshows y la comedia política (Gómez \& Renero, 2003; Hernández \& Orozco, 2007). La iniciativa de crear el segmento de parodia Hechos de peluche (1996) dentro del noticiario principal de Azteca vino del dueño de Televisión Azteca, Ricardo Salinas Pliego, tras volver de un viaje en donde había visto programas similares: por esta 
época ya existían en España Las noticias del guiñol y, en Colombia, Los reencauchados, ambos a su vez adaptaciones del programa británico Spitting Image.

Si bien se seguía una fórmula, los peluches fueron para la sátira televisiva mexicana un hito, pues por primera vez se personificaba a actores políticos identificables, con la salvedad de que no contó con un títere del entonces presidente de la República, Ernesto Zedillo, "por respeto a la figura presidencial" (Ortiz, 1997, 31 de mayo). Las opiniones y burlas de Hechos de peluche estaban "siempre cargadas en contra del perredismo y su líder [...] y de las posturas de izquierda, y a favor en un principio del PRI y hoy del PAN y de Vicente Fox" (Toussaint, 2000, 28 de octubre). Además del éxito comercial y de audiencias, hubo incidentes concretos de presión para incidir en los contenidos del sketch por parte de políticos (Mérida, 2016, 25 de noviembre; Tiempo de Michoacán, 2018, 6 de noviembre).

Al momento de lanzar Hechos de peluche, Televisa no tenía ningún programa de sátira política (Martínez Arias, 2006). Fue hasta la reestructuración del noticiario estelar, en la que el perenne Jacobo Zabludovsky fue sustituido por Joaquín López-Dóriga, cuando, con un estilo aún más domesticado e inofensivo, Televisa integró la sátira política a su noticiero estrella a través del segmento de diez minutos Las mangas del chaleco (Televisa, 2000), un pastiche de clips recientes y de archivo que hacía mofa de las frases absurdas pronunciadas por los políticos durante la semana.

\subsection{Televisoras y el gobierno federal: un nuevo modelo de relación}

Indicios de un renovado pacto entre las televisoras y el gobierno federal fueron interpretados como una nueva era en las relaciones gobierno-televisoras en la que Televisa, bajo el liderazgo de Emilio Azcárraga Jean, dejó de ser partidaria fiel y aliada del PRI y pasó a convertirse, al lado de Azteca, en "protagonista" de la política mexicana (Hernández \& Orozco, 2007). De acuerdo con esta hipótesis, el súbito cambio de actitud de Televisa hacia la institución presidencial manifestado en 2002 en la inaudita revelación de una grabación telefónica que ridiculizaba (sin ser parodia) al presidente Vicente Fox (el famosísimo "comes y te vas")— fue la táctica de presión para empujar un nuevo intercambio de mutuo beneficio.iii Este pacto comprendió, en favor de las televisoras: en primer lugar, la eliminación de la competencia, al permitir la Secretaría de Comunicaciones y Transportes que Azteca asaltara y destruyera las instalaciones del joven canal CNI40 por incumplimiento de contrato (diciembre de 2002); y en segundo lugar, dos reformas que favorecían a las televisoras disminuyendo el tiempo fiscaliv (octubre de 2002) y destrabando, mediante la "ley Televisa", los obstáculos que impedían a los grandes jugadores de siempre incursionar en nuevos mercados mediante la convergencia digital (diciembre de 2006).

Los mismos nuevos aires mediáticos llevaron a Víctor Trujillo, el payaso Brozo, en su nueva faceta de comentarista punzante de la actualidad, de la radio a la televisión. Primero, a El diario de la noche (Azteca, 1995) y después a El mañanero (CNI40, 2000). Este último, histórico por ser el primer telenoticiario mexicano conducido por un comediante, pronto cesó de transmitirse en CNI40, una pequeña estación de televisión asfixiada por falta de dinero. Entonces, Trujillo trasladó el proyecto al canal 4 de Televisa a partir de 2002, formando parte así del esfuerzo del nuevo presidente del emporio de medios, Emilio Azcárraga Jean, por renovar a la desprestigiada cadena mediante la incorporación de "otras voces que nunca han tenido que ver con Televisa o incluso que han sido opositoras" (Caballero, 2002, 3 de enero).

Trujillo desarrolló en Brozo un personaje desfachatado, cínico, misógino y carente de empacho para vociferar reclamos sociales y proferir una ácida crítica hacia la clase política. En marzo de 2004 destapó en una transmisión en vivo uno de los célebres videos que contribuyeran a la posterior derrota electoral de quien fuera candidato presidencial de izquierda, Andrés Manuel López Obrador. Esto, en un episodio considerado la cúspide del uso de la televisión para 
manipular la opinión pública a través de una serie de videograbaciones de transgresiones de funcionarios públicos relacionados con la administración de López Obrador, entonces jefe de gobierno del Distrito Federal (Hernández Navarro, 2006; Alonso, 2015).

La amalgama de rasgos del payaso también dio licencia a Trujillo para desplegar una misoginia que se manifestaba no solamente en el machismo del albur -típico de la comedia mexicanasino en el habitual trato objetificador de las mujeres dentro de El mañanero, en donde estas aparecían como silentes edecanes semidesnudas o como entrevistadas que eran objeto de minimización. Desarrollado a través de una larga trayectoria que incluye numerosos programas que satirizan la realidad, en el estilo de Brozo pervive la tensión entre la crítica subversiva al poder y el cinismo pragmático influenciado por las lógicas del mercado y los intereses corporativos de Televisa, puesto que "es evidente que su discurso crítico opera dentro de los marcos comerciales de la estructura capitalista del gigante mediático" (Alonso, 2015, p. 85).

Nuevos fenómenos provocaron la expansión de la mediatización de la política y la persistencia de la instrumentalización de la televisión abierta. Otro elemento clave de la nueva relación entre las televisoras y el gobierno federal tras la alternancia política fue el creciente uso de la mercadotecnia política (Mejía, 1999) y, por consiguiente, el incremento incesante del gasto público en anuncios publicitarios, que tras la alternancia política en la presidencia no dejaría de aumentar sexenio tras sexenio. En el ámbito electoral, el financiamiento creciente de prerrogativas para los partidos políticos hizo que "La vida política y las elecciones se volvieron muy caras en el país", lo cual implicó una transferencia de recursos públicos a las organizaciones de medios "a medida que... ocuparon una mayor centralidad en la lucha por el poder político" (Buendía \& Azpiroz, 2011, p. 41). La importancia de los medios, así como el limitadísimo número de jugadores en la industria televisiva, dio a las organizaciones de medios ventajas en su negociación con los partidos políticos, pues podían otorgar una cobertura informativa en función de los recursos recibidos por publicidad (Buendía \& Azpiroz, 2011). Esta situación fue el origen de los desequilibrios de poder que han estado detrás del descomunal aumento del gasto público en publicidad, no solo del gobierno federal sino también de los gobiernos de los estados.

Los contenidos televisivos no solo fueron incorporados a las estrategias de campañas políticas en forma de anuncios publicitarios, sino también mediante nuevas tendencias, como el product placement (propaganda disfrazada) y el social merchandising en la ficción televisiva y la participación de políticos y candidatos en los programas de variedades (Franco, 2012). Un episodio claro de product placement durante el proceso electoral 2005-2006 fue el mensaje proselitista de un personaje dentro de la telenovela La fea más bella, el cual era el programa con mayores niveles de audiencia en junio de 2006 (García-Rubio, 2009; Baños \& Carriedo, 2010; Pareja-Sánchez, 2012).

En este marco es que Televisa produce meses antes de la elección presidencial de 2006 el programa de parodia política El privilegio de mandar, una telenovela seriada con contenido político que satiriza los acontecimientos de la política mexicana ocurridos la semana anterior (Molina, 2005) realizada por talento proveniente de telenovelas y programas cómicos apolíticos. El privilegio tuvo un enorme éxito de audiencias: su rating ${ }^{v}$ era mayor al del noticiario estelar de Televisa (Espino, 2007; Molina, 2005); asimismo, de acuerdo con una encuesta nacional, $73 \%$ de la población declaró haber visto el programa y $75 \%$ declaró que el programa proporcionaba mucha o algo de información sobre la situación política del país (Parametría, 2005, 31 de agosto). La notoriedad del programa dio pie a preguntas acerca de la contribución del programa al flujo de información en el contexto electoral. Comentaristas se centraron en lamentar la superficialidad del humor (dirigido principalmente hacia la apariencia física y los vicios de carácter de políticos), la ausencia de sátira contra la élite económica y el sesgo en los contenidos (Molina, 2005; Espino, 2007). 
Esta última acusación se basó en que el programa dedicaba espacio significativo a alusiones a los videoescándalos políticos que en 2004 habían llegado a los titulares y, en general, a los temas asociados a la campaña negativa contra el candidato López Obrador (Espino, 2007). El episodio más controvertido sería, sin embargo, el último, transmitido tras la jornada electoral de 2006. En las mencionadas elecciones, López Obrador fue derrotado por un estrechísimo margen de 0.62 por ciento. Al final del episodio de El privilegio, el personaje de Canti cierra la temporada rompiendo la cuarta pared para dar un discurso al verdadero López Obrador y las audiencias en el que desaprueba el plan de buscar la impugnación de la elección presidencial y en el que pondera la importancia de aceptar el resultado electoral "porque así es la democracia". La cercanía Televisa-PAN construida en los años anteriores a la elección de 2006 (Gameros, 2009; Hernández \& Orozco, 2007) hace factible y creíble el sesgo de El privilegio.

El proceso electoral de 2006 y sus resultados provocaron discusiones en torno al uso instrumental de la televisión y los medios de comunicación para influenciar las votaciones y serían el origen de una posterior reforma electoral para prevenir excesos en los siguientes comicios.

\subsection{La sátira tras las elecciones presidenciales de 2006}

Tras el controvertido episodio final de El privilegio de mandar (2005) y con excepción de Víctor Trujillo, productores desistieron de producir programas de televisión de sátira política en parte por su relativa baja rentabilidad (altos costos y baja exportabilidad), en parte por la coyuntura post electoral. Se observaba, dicen comentaristas, un entorno "enrarecido y polarizado" (Krauze, 2017, 17 de julio) en el que "se venía un momento álgido, y en esos casos es mejor hacerse a un lado" (Milenio, 2012, 23 de junio).

Adicionalmente, la reforma electoral de 2007-2008 intentó prevenir futuros excesos al prohibir que actores políticos y terceros adquirieran propaganda política. ${ }^{\mathrm{vi}}$ Este endurecimiento de la regulación electoral provocó cierta incertidumbre, que fue esgrimida como otra razón del déficit de humor político durante los años posteriores a 2006: "con muchas de las más recientes reformas que se estuvieron autorizando hay que tener el triple de cuidado para manejar contenidos políticos en medios tradicionales... [Si] fuera tan fácil, ¿por qué nadie más lo está haciendo?” (Cueva, 2015, 11 de febrero).

Pero, además de lo anterior, indicios apuntan a una persistente autocensura. Uno de estos fue la sonora acusación de censura del comediante Héctor Suárez a productores del programa Iniciativa México. ${ }^{\text {vii }}$ Otro incidente fue el fallido proyecto de producir en Televisa una adaptación mexicana de Saturday Night Live, una suerte de fracaso anunciado por la falta de libertad para producir humor político en la televisión abierta mexicana y el alto costo que implicaba operar la franquicia estadounidense (Quijano, 2015, 18 de julio; Dispara Margot Dispara, 2017, 11 de mayo).

Así, los programas de humor político han tendido a transmitirse principalmente durante los procesos electorales: El privilegio de mandar estrenó su segunda temporada en 2018. Azteca, por su parte, agregó sátira a su programación con la transmisión — siempre durante las temporadas electorales - de Campañeando $(2011,2015,2018)$, mesa de periodistas que comentan humorísticamente clips de declaraciones y deslices de actores políticos en el contexto de las campañas electorales. La adaptación de la fórmula del exitoso programa sobre farándula Ventaneando hace patente el enfoque consistente en tratar la política como espectáculo.

Durante el periodo posterior a 2006, la sátira política se manifestó en espacios de televisión fuera del duopolio Televisa-Azteca. Uno de ellos fue el canal Cadenatres (creado en 2007 y que eventualmente se convertiría en Imagen, la tercera red de televisión en México). Esta estación apostó por programas que transpiraron una fuerte influencia de las fórmulas probadas de sátira de los programas nocturnos estadounidenses de variedades. Mikorte informativo, El incorrecto, Ya ni 
Ilorar es bueno y Qué importa conformaron una la "barra desinformativa" de programas en la que se hablaba "de todo siempre y cuando sea divertido; si es de güeva, no" con un estilo más conservador que subversivo, como se entrevé en la declaración del conductor de Ya ni llorar es bueno: "¿Por qué tenemos que estarnos quejando siempre?; sí aquí estamos, hay que divertirnos" (Díaz, 2014, 27 de abril).

\subsection{8 y más allá: un panorama mixto}

Como parte del paquete de reformas impulsado por el presidente Enrique Peña Nieto — conocido como "pacto por México"- fueron promulgadas una reforma constitucional en materia de telecomunicaciones en 2013 y al año siguiente una nueva Ley Federal de Telecomunicaciones y Radiodifusión que en materia de televisión reemplazaba a la Ley Federal de Radio y Televisión de 1960. Aunque esta reforma significó un avance significativo en los sectores mediáticos al establecer mecanismos para frenar la concentración, el gobierno de Peña se caracterizó al mismo tiempo por escándalos de corrupción y gastos millonarios en publicidad que indicaron la persistencia de prácticas clientelares difíciles de erradicar (Gómez, 2020).

Con 23.4 puntos de share, ${ }^{\text {viii }}$ el relanzamiento de El privilegio de mandar en 2018 superó en audiencias a Campañeando y Qué importa, los otros dos programas de humor político al aire en ese momento (Televisa, 2018, 30 de enero). A pesar de que este programa representaba continuamente al presidente Peña Nieto, el mecanismo de los chistes era la burla hacia la falta de cultura y errores al hablar de esta figura política, así como el uso de pueriles juegos de palabras. En este programa, los chistes verdaderamente hirientes (por hacer referencia directa a actos de corrupción) estaban reservados para figuras ya caídas en desgracia, como lo fue el gobernador de Veracruz Javier Duarte, preso por corrupción. Otro elemento constante fue el ciudadano común, representado por el personaje de Márgara Francisca, que insultaba a políticos diciéndoles sus "verdades".

Así, incluir chistes sobre todo tipo de actores y asuntos políticos fue insuficiente: la falta de chistes que desafiaban a poderosos, los bajos valores de producción y la pérdida de audiencias y de credibilidad de Televisa, aunados a la carencia de un contexto de alta competitividad electoral que alentara la polémica sobre la influencia de este programa en el electorado, contribuyeron a que esta nueva versión de El privilegio estuviera lejos de ser un éxito de crítica.

Otro lugar para la sátira fue la televisión pública. En un género inexplorado en los sistemas públicos de medios desde la desaparición de Imevisión, la televisión pública resolvió el recuperar una marca de humor político más comprometido ideológicamente a través de talk shows como El chamuco tv (TV UNAM y Canal 22, 2018), John y Sabina (Canal Once, 2019) y La maroma estelar (Canal Once, 2019).

Los últimos dos programas mencionados formaron parte de las novedades tras el cambio de administración federal. En el contexto del abrumador triunfo electoral de Andrés Manuel López Obrador, estos programas fueron objeto de críticas de parte de opositores y comentaristas que se centraban en cuatro puntos. El primero es que ambos programas recuperaron, reprodujeron y examinaron las categorías sociales chairos y fifís, usadas por el presidente López Obrador para referirse a la diferencia de clases y la desigualdad en el país, pero que también generaron escozor entre quienes las consideraban parte de una retórica que alimentaba la polarización y la crispación en el debate público.

En segundo lugar, en ambos programas predominó el tono propagandista favorable a la administración de López Obrador, que se manifestó en el talento, la selección de entrevistados (funcionarios y personas afines al gobierno federal) y temas, todo desde un enfoque de izquierda, esto último novedoso en la televisión mexicana. El tercer punto fue el tipo humor utilizado. El 
principal reproche fue contra la parodia realizada en La maroma estelar a Denise Dresser, académica y activista. El humor se basó primordialmente en sus rasgos personales (su físico, su forma de hablar), aunque también recogía sus opiniones y nexos. La crítica denunció el desbalance de poder implicado en el acto de burlarse de una mujer que participa en lo público desde la sociedad civil, que los creadores justificaban aludiendo a los nexos de Dresser con Claudio X. González, un poderoso empresario opositor de López Obrador y financiador de influyentes think tanks mexicanos.

El cuarto y último punto es el uso de recursos públicos para producir los contenidos problemáticos arriba descritos, cuestión que coloca en una posición vulnerable a la sátira producida por canales públicos. Después de críticas y de diferencias en el equipo —el comediante Carlos Ballarta llegó a decirse limitado-, el programa La maroma estelar fue cancelado.

Mientras tanto, el aumento de hogares con banda ancha en el país proporcionó el sustento material para el crecimiento tanto del consumo como de la producción de televisión por internet a través de plataformas como Youtube. Influenciado por la sátira política estadounidense que podía verse en canales de cable como Comedy Central y por el éxito de sus bromas políticas en Twitter, Manuel Torres Chumel comenzó a producir de forma casera el falso noticiario El pulso de la república en diciembre de 2012 en Youtube, justo al inicio del gobierno de Enrique Peña Nieto. El enorme éxito de la crítica satírica de Torres — dirigida principalmente contra el gobierno federalabrió las puertas para que numerosos creadores buscaran probar éxito produciendo programas con contenidos políticos en la misma plataforma. Asimismo, evidenció las limitaciones creativas y de libertad de la sátira política creada para la televisión abierta, pues en esta última las parodias y críticas dirigidas hacia el entonces presidente Peña Nieto se referían únicamente a aspectos superficiales en vez de a los grandes escándalos de su gobierno.

\section{Conclusiones}

En este trabajo se buscó construir una narrativa del desarrollo de la sátira televisiva en México como herramienta para identificar las maneras en que esta forma de discurso reproduce las condiciones de los sistemas políticos y de medios en el marco de la transición democrática. En rigor, la sátira televisiva mexicana no inicia de cero en el periodo post autoritario, pues hay antecedentes de sátira televisiva que datan de fechas previas; precedentes con características peculiares: cierta crítica social, sin alusiones directas a actores políticos (ni individuales ni institucionales), mucho menos sobre el presidente de la república. Con todo, la producción de sátira durante el periodo postautoritario bien podría calificarse de auge, dados la cantidad de programas realizados y la apertura en contenidos, pues es hasta la segunda mitad de 1990 que creadores y dueños de medios (en su papel de gatekeepers) (Shoemaker \& Reese, 2014) se atreven a producir humor en el que se burlen directamente de actores políticos de relevancia.

Sin embargo, tal auge cobra los matices de las condiciones particulares del caso mexicano, pues el humor producido durante el periodo de transición política permaneció constreñido e influenciado principalmente por cinco elementos: las relaciones clientelares entre las televisoras y los actores políticos, la autocensura, las orientaciones políticas de los medios, las consideraciones comerciales y los rituales profesionales.

En primer lugar, fueron ampliamente documentadas las relaciones clientelares entre las televisoras y diferentes actores políticos durante el periodo, principalmente el gobierno federal en turno, que incluyeron la regulación a modo y, tras la alternancia política, un creciente gasto público en propaganda mediática ocasionado asimismo por el desequilibrio de poder entre actores políticos y televisoras, pues la alta concentración del mercado de la televisión abierta elevó los precios de la publicidad en televisión en un contexto de alta competitividad electoral. De esta manera se constata la continuidad de la ya prevaleciente tendencia de alinear los contenidos 
televisivos a los intereses económico-políticos de las televisoras. En el periodo analizado, la cercanía entre Televisa y el gobierno federal liderado por actores del PAN se manifestó en los programas de sátira: la ola de videoescándalos relacionados con la corrupción de funcionarios de la Ciudad de México tuvo su punto más álgido en la confrontación entre Víctor Trujillo y René Bejarano en El mañanero. Junto con el anterior, el discurso desaprobatorio de la impugnación en El privilegio de mandar puede interpretarse como producto de las relaciones clientelares entre televisoras y actores políticos.

En segundo lugar, las relaciones institucionales de la organización de medios son generadoras de autocensura, practica en la que los propios creadores anticipan qué contenidos tienen el potencial de ser problemáticos para la organización de medios y evitan realizarlos, generando una situación en la que es innecesario que autoridad alguna ejerza presión o censura y que tiene como resultado un control bastante efectivo sobre los contenidos (Fernández y Paxman, 2013). Si bien en 1996 comienza la personificación de actores políticos en sketches paródicos, el vicepresidente de noticiarios de Azteca explicaba que aún no había peluche del presidente por el respeto de la televisora hacia la figura presidencial. Varios episodios evidenciaron la persistencia de la autocensura en las organizaciones de medios en años recientes; tal vez la demostración más elocuente de esta fue el desinterés por realizar comedia política en televisión abierta a pesar de los éxitos de audiencias de El privilegio de mandar en 2005-2006 y del programa de Youtube El pulso de la república, iniciado en 2012.

Tercero, las consideraciones comerciales de la organización de medios incluyen la preferencia por contenidos que sean rentables, como lo son aquellos que son atractivos y entendibles para las grandes audiencias, así como exportables a otros mercados televisivos. Esta fue una de las razones esgrimidas para dejar de hacer sátira tras 2006. La importación de formatos televisivos de sátira, la cual verifica la relevancia de las tendencias de orden global, tuvo como causa, al menos en el caso de Azteca, las consideraciones comerciales emanadas de la necesidad de hacer rentable y sostenible a la segunda cadena televisiva de México.

Cuarto, en estrecha asociación con las anteriores están las orientaciones políticas prevalecientes en las organizaciones de medios. En la sátira realizada en televisoras privadas, actitudes como el conservadurismo, la frivolidad y el cinismo político se manifiestan en los contenidos y se evidencian en los testimonios de creadores apoyando la producción de comedia política ligera que funja como distracción para las personas. Los canales públicos, por su parte, fueron objeto de crítica en 2019 por producir una comedia partidaria de izquierda cercana a la propaganda.

En quinto y último lugar, también dan forma a los contenidos ciertos rituales profesionales que buscan proteger a las organizaciones de medios de acusaciones de sesgos y falta de profesionalismo. A la manera del periodismo, en la sátira política el atacar a todos por igual permite aparentar neutralidad o al menos ausencia de sesgo. Sin embargo, atacar a todos en igual cantidad no garantiza el balance, pues los chistes de tono más agresivo pueden dirigirse a actores políticos de manera selectiva, algo que en su momento comentaristas advirtieron sobre parodias como Hechos de peluche y El privilegio de mandar.

La historia no es lineal, ni es un progreso acumulado; el devenir está lleno de tropiezos, altibajos, regresiones y paradojas. El transitar de la sátira no es la excepción. Pero, además, su retórica de juego hace a la sátira el género propicio para encontrar ambigüedades de sentido que vuelven sumamente complejo el evaluar sus aportes: un mismo chiste puede tener varias interpretaciones. Incluso, el satirista puede ser interpretado de manera diferente a como planeó: una sátira que pretende denostar puede tomarse como una apología o incluso favorecer la popularidad del objeto de sátira. A pesar del riesgo que implican los dos puntos anteriores, el presente análisis ofrece elementos para concebir la limitada libertad con la que operaron los programas de sátira en la televisión abierta en el periodo de transición democrática como un espacio que debe su 
complejidad y constante transformación a una conjunción de condiciones de orden institucional y organizacional.

\section{Referencias}

Alonso, P. (2015). Infoentretenimiento satírico en México: el caso de Brozo, el Payaso Tenebroso. Cuadernos.info, (37), 77-90. doi: http://dx.doi.org/10.7764/cdi.37.820

Alzate, G. A. (2010). Dramaturgy, citizenship, and queerness: Contemporary Mexican political cabaret. Latin American Perspectives, 37(1), 62-76. doi: http://dx.doi.org/10.1177/0094582X09351710

Baños, M. A., \& Carriedo, L. M. (2010). Distorsiones de la propaganda política. Revista Justicia Electoral, 1(5), 129-147.

Barajas, R. \& Valdés Peña, J. A. (2016). ¿Actuamos como caballeros o como lo que somos? El humor en el cine mexicano. México: Cineteca Nacional.

Baym, G., \& Jones, J. (2012). News Parody in Global Perspective: Politics, Power, and Resistance. Popular Communication, 10(1-2), 2-13. doi: http://dx.doi.org/10.1080/15405702.2012.638566

Becker, A. B. (2012). Comedy Types and Political Campaigns: The Differential Influence of OtherDirected Hostile Humor and Self-Ridicule on Candidate Evaluations. Mass Communication and Society, 15(6), 791-812. doi: http://dx.doi.org/10.1080/15205436.2011.628431

Bruun, H. (2012). Political satire in Danish television: Reinventing a tradition. Popular Communication, 10(1-2), 158-169. http://dx.doi.org/10.1080/15405702.2012.638568

Buendía, J. \& Azpiroz, J. M. (2011). Medios de comunicación y reforma electoral 2007-2008. México: Tribunal Electoral del Poder Judicial de la Federación.

Caballero, J. (2002, 3 de enero). Nunca me habían mentado tanto la madre por e-mail, asegura Brozo. La Jornada.

Cueva, A. (2015, 11 de febrero). ¿Qué le hicieron a "Campañeando"? Milenio.

Del Collado, F. (2013, 9 de junio). En la política 'hay muy buenos comediantes': Héctor Suárez. Milenio.

Díaz, E. (2014, 27 de abril). 'Barra desinformativa': risa, sátira y mucha diversión. Excélsior. Recuperado el 1 de junio de 2020 de https://www.excelsior.com.mx/funcion/2014/04/27/956012

Dinç, E. (2012). On the limits of oppositional humor: The Turkish political context. Middle East Journal of Culture and Communication, 5(3), 322-337. doi: http://dx.doi.org/10.1163/1873986500503012

Dispara Margot Dispara (2017, 11 de mayo). Televisa cancela Saturday Night Live México. Recuperado el 1 de junio de 2020 de https://www.youtube.com/watch?v=GAKo76PBuRA

Espino, G. (2008). El nuevo escenario de la comunicación política en las campañas presidenciales de México. Tesis doctoral. Universitat Autònoma de Barcelona.

Estrada, C. (2011). Una vida de telenovela. En Cueva, A., Estrada, C., Garnica, A., Jara, R., López, H., Orozco, G. \& Soto, S. Telenovelas en México. Nuestras íntimas extrañas (45-90). México: Grupo Delphi.

Feldman, L. (2007). The news about comedy: Young audiences, The Daily Show, and evolving notions of journalism. Journalism, 8(4), 406-427. doi: http://dx.doi.org/10.1177/1464884907078655 
Fernández, C. \& Paxman, A. (2013). El tigre: Emilio Azcárraga y su imperio Televisa. México: Grijalbo.

Franco Migues, D. (2012). Ciudadanos de ficción: discursos y derechos ciudadanos en las telenovelas mexicanas. El caso Alma de Hierro. Comunicación y sociedad, (17), 41-71.

Gameros, M. (2009). Politics as Entertainment in Mexico. In M. A. Guerrero \& M. Chavez, Empowering citizenship through journalism, information, and entertainment in Iberoamerica, 199220. Universidad Iberoamericana.

García-Rubio, C. (2009). Reforma electoral y televisión. Los formatos de los mensajes políticos después de la reforma electoral. El Cotidiano (155), 5-11.

Gómez, R. (2020). El rol del Estado en el Sistema de Medios Mexicano 2013-2018. Punto de partida para una agenda de investigación. Comunicación y Sociedad, 1-28. doi: https://doi.org/10.32870/cys.v2020.7565

Gómez Rodríguez, G. \& Renero Quintanar, M. M. (2003). TV global y espectáculos locales. Guadalajara: Universidad de Guadalajara.

Guerrero, M. A., \& Marquez, M. (2014). The "Captured-Liberal” Model: Media Systems, Journalism and Communication Policies in Latin America. In M. A. Guerrero \& M. Marquez (Eds.), Media Systems and Communication Policies in Latin America. New York: Palgrave McMillan.

Hallin, D. C., \& Mancini, P. (2004). Comparing media systems: Three models of media and politics. Cambridge university press.

Hernández L., F. \& Orozco G., G. (2007). Televisiones en México. Un recuento histórico. México: Universidad de Guadalajara.

Hernández Navarro, L. (2006). Images of the Dirty TV-War: The Hour of Mediacracy. Latin American Perspectives, 33(2), 70-77. doi: http://dx.doi.org/10.1177/0094582X05286086

Holbert, R. L., Hmielowski, J., Jain, P., Lather, J., \& Morey, A. (2011). Adding nuance to the study of political humor effects: Experimental research on juvenalian satire versus horatian satire. American Behavioral Scientist, 55(3), 187-211. doi: http://dx.doi.org/10.1177/0002764210392156

Hughes, S., Mellado, C., Arroyave, J., Benitez, J. L., de Beer, A., Garcés, M., ... \& MárquezRamírez, M. (2017). Expanding influences research to insecure democracies: How violence, public insecurity, economic inequality and uneven democratic performance shape journalists' perceived work environments. Journalism Studies, 18(5), 645-665. doi: https://doi.org/10.1080/1461670X.2016.1266278

Ibrahim, A., \& Eltantawy, N. (2017). Egypt's Jon Stewart: Humorous Political Satire and Serious Culture Jamming. International Journal of Communication, 11, 2806-2824.

Krauze, E. (2017, 17 de julio). Héctor Lechuga: el humor inteligente. Reforma.

Kuhlmann, J. (2012). Zimbabwean diaspora politics and the power of laughter: Humour as a tool for political communication, criticism and protest. Journal of African Media Studies, 4(3), 295-314. doi: http://dx.doi.org/10.1386/jams.4.3.295 1

LaMarre, H. L., Landreville, K. D., Young, D., \& Gilkerson, N. (2014). Humor Works in Funny Ways: Examining Satirical Tone as a Key Determinant in Political Humor Message Processing. Mass Communication and Society, 17(3), 400-423. doi: http://dx.doi.org/10.1080/15205436.2014.891137

Lawson, C. (2002). Building the Fourth Estate: Democratization and the Rise of a Free Press in Mexico. Berkeley: University of California Press. 
Levitsky, S., \& Way, L. A. (2010). Competitive authoritarianism: Hybrid regimes after the Cold War. Cambridge University Press.

Martin, A., Kaye, B. K., \& Harmon, M. D. (2018). Silly meets serious: discursive integration and the Stewart/Colbert era. Comedy Studies, 9(2), 120-137. doi: https://doi.org/10.1080/2040610X.2018.1494355

Martínez Arias, E. (2006, 25 de junio). Hacen divertida la política. El Siglo de Torreón.

Mejía Barquera, F. (1999). Televisión y política. En Sánchez de Armas, M. A. \& Ramírez, M. P. (1999). Apuntes para una historia de la televisión mexicana II (21-66). México: Revista Mexicana de Comunicación.

Mérida, J. (2016, 25 de noviembre). Los peluches contra la censura. El Universal.

Milenio (2012, 23 de junio). Frenan comedia política en televisión. Milenio.

Molina, T. (2005, 16 de octubre). El privilegio de mandar... en los hogares mexicanos. La Jornada.

Ortiz P., F. (1997, 31 de mayo). En "Hechos de Peluche" no aparece el muñeco de Ernesto Zedillo por "respeto a la figura presidencial": Sergio Sarmiento. Proceso.

Otto, L., Glogger, I., \& Boukes, M. (2017). The softening of journalistic political communication: A comprehensive framework model of sensationalism, soft news, infotainment, and tabloidization. Communication Theory, 27(2), 136-155. doi: http://dx.doi.org/10.1111/comt.12102

Parametría (2005, 31 de agosto). El Privilegio de Mandar: ¿nueva forma de informarse? Recuperado el 1 de junio de 2020 de http://www.parametria.com.mx/estudios/el-privilegio-demandar-nueva-forma-de-informarse/

Pareja Sánchez, N. (2012). Los nuevos espacios de la comunicación política en el proceso electoral de 2012 en México. La ficción televisiva y la Reforma Electoral de 2007-2008. Revista Mexicana de Opinión Pública, (12), 13-29.

Quijano, J. A. (2015, 18 de julio). Política, vetada en la comedia mexicana: Derbez. Recuperado el 1 de junio $\quad$ de 2020 de https://www.eluniversal.com.mx/articulo/espectaculos/television/2015/07/18/politica-vetada-en-lacomedia-mexicana-derbez

Rodelo, F. (2020). El pulso de la república y los programas mexicanos de sátira política y periodismo ciudadano en Youtube, ¿la respuesta mexicana a Jon Stewart? In G. Orozco (ed.), La TV en tiempos de Netflix. La nueva oferta mediática. Guadalajara: Universidad de Guadalajara.

Scherer, J. (1986). Los presidentes. México: Grijalbo.

Schmidt, S. (1996). Humor en serio: análisis del chiste político en México. México: Aguilar.

Semati, M. (2012). The Geopolitics of Parazit, the Iranian Televisual Sphere, and the Global Infrastructure of Political Humor. Popular Communication, 10(1-2), 119-130. doi: http://dx.doi.org/10.1080/15405702.2012.638581

Shoemaker, P. J., \& Reese, S. D. (2014). Mediating the message in the 21st century: Theories of influence on mass media content. New York: Routledge.

Televisa (2018, 30 de enero). El privilegio de mandar estrena como líder de audiencia. Recuperado el 1 de junio de 2020 de https://www.televisa.com/sala-deprensa/series/1030570/privilegio-mandar-estrena-lider-audiencia

Tiempo de Michoacán (2018, 6 de noviembre). "Hechos de Peluches", una época de libertad expresión dentro de la comedia mexicana. 
Toussaint, F. (1986, 19 de abril). ¿Qué nos pasa? Proceso.

Toussaint, F. (2000, 28 de octubre). Los guiñoles o peluches. Proceso.

Trejo, R. (2014). Televisa: viejas prácticas, nuevo entorno. Nueva Sociedad, (249), 149-162.

TVUDLAP (2016). Víctor Trujillo para El Interrogatorio Versión Extendida TVUDLAP [video]. Recuperado el 5 de junio de 2020 de https://www.youtube.com/watch?v=rhqK9qlG-ql\&t=3327s

Waisbord, S. (2014). Latin America Media and the Limitations of the Media 'Globalization' Paradigm. En M. A. Guerrero \& M. Marquez (Eds.), Media Systems and Communication Policies in Latin America (24-42). New York: Palgrave McMillan.

Zona Franca (2011, 7 de noviembre). Héctor Suarez acusa de censura a Televisa y emite carta pública para Emilio Azcárraga Jean. Recuperado el 1 de junio de 2020 de https://zonafranca.mx/radar/hector-suarez-acusa-de-censura-a-televisa-y-emite-carta-publicapara-emilio-azcarraga-jean/

\title{
NOTAS
}

\begin{abstract}
'Aunque esta tampoco se salvaba del hiperpresidencialismo mexicano. Comenta Scherer (1986, p. 81): "Tema inevitable fue la libertad de prensa. Dije que sólo en breves periodos de nuestra historia se había ejercido sin cortapisas. Me impresionaba en lo personal el caso de los caricaturistas. Maestros de su oficio, herederos de Posada y Orozco, perdían la soltura al enfrentar al presidente. Ellos, que todo satirizan y tocan, pasaban por alto al gran personaje y lo dejaban ir. Muy pocos, admirables, escapaban a esta limitación evidente".

ii La productora de telenovelas Carla Estrada (2011, pp. 78-79) relata un ejemplo del nivel al que podía llegar la censura de la Secretaría de Gobernación hacia contenidos de otro género, el de la telenovela: "En ese entonces la Secretaría de Gobernación tenía mucha injerencia en el contenido de las historias y hacía una minuciosa supervisión, revisaba y modificaba los libretos, enviaba representantes a las grabaciones que incluso repasaban el capítulo editado y le hacían más cambios antes de salir al aire. Por ejemplo, estaba prohibido mencionar la palabra amantes o que estos personajes aparecieran en una recámara sentados en la cama o acostados [...] Nunca supimos si fue el éxito de Quinceañera [telenovela producida en 1987], la denuncia social o el hecho de ser una telenovela juvenil lo que nos convirtió en el blanco de Gobernación en ese entonces. Las prohibiciones comenzaron desde que conocieron la historia, en cuyo original se hablaba de una violación a la protagonista. Sin embargo, los responsables del Departamento de Televisión en esa Secretaría no permitieron que se tocara así el tema, aunque dos años antes lo consintieron en otras telenovelas como Muchachita, [...] en la cual violaban al personaje".

iii Trejo (2014) lo explica de la siguiente manera: "el sistema político mexicano se diversificaba y ahora los intereses de Televisa no siempre podrían gestionarse en acuerdos personales y discrecionales con los presidentes de la República y sus funcionarios más cercanos" (p. 157).

iv Impuesto en especie que consiste en una proporción del tiempo aire total y que se aplicó en México a la radio y a la televisión radiodifundidas.

${ }^{\vee}$ Porcentaje de audiencias sintonizando como parte de la población total en el país.

vi Esta tuvo entre sus características la prohibición de campañas negativas (se elevó a rango constitucional la prohibición de expresiones denigratorias de las instituciones y partidos políticos y las calumnias contra personas), el acceso de los partidos políticos a los medios de comunicación, la prohibición de la contratación de propaganda electoral, y la prohibición de la guerra sucia (Buendía \& Azpiroz, 2011, pp. 33 y ss.).

vii Suárez hizo pública su protesta en una carta dirigida a Emilio Azcárraga Jean, presidente de Televisa: "la esencia de la comedia es, por antonomasia, crítica y burla. No se puede pretender hacer reír al público, sin ejercer dichos elementos, y menos con el temor de 'molestar a alguien'. Actitud moralista, temerosa y prejuiciosa constante de los Galindo; de ahí los repetidos desacuerdos que tuve con los mencionados productores" (Zona Franca, 2011, 7 de noviembre).

viii Porcentaje de audiencias sintonizando el programa con relación al total de audiencias usando televisor.
\end{abstract}

